DEMOGRAPHIC RESEARCH

VOLUME 30, ARTICLE 9, PAGES 277-312

PUBLISHED 28 JANUARY 2014

http://www.demographic-research.org/Volumes/Vol30/9/

DOI: $10.4054 /$ DemRes.2014.30.9

Research Article

\title{
Modelling the constraints on consanguineous marriage when fertility declines
}

\section{Bilal Barakat \\ Stuart Basten}

(C) 2014 Bilal Barakat \& Stuart Basten.

This open-access work is published under the terms of the Creative Commons Attribution NonCommercial License 2.0 Germany, which permits use, reproduction \& distribution in any medium for non-commercial purposes, provided the original author(s) and source are given credit.

See http:// creativecommons.org/licenses/by-nc/2.0/de/ 


\section{Table of Contents}

$1 \quad$ Background 278

$\begin{array}{ll}1.1 & \text { Defining consanguinity } \\ 1.278\end{array}$

1.2 Recent trends in consanguinity 282

2 Methods 284

2.1 Baseline distribution 284

2.2 Model specification adjustments 284

2.3 Sex ratio 285

$2.4 \quad$ Son preference stopping rule 285

2.5 Childlessness 286

2.6 Correlated sibling fertility 286

2.7 Selectivity 286

$3 \quad$ Analysis and results 287

3.1 Overall relationship between fertility and pool of male cousins 287

3.2 Probabilities of no male cousin 289

$\begin{array}{lll}3.3 & \text { Matching } & 290\end{array}$

$\begin{array}{lll}3.4 & \text { Country case studies } & 296\end{array}$

$4 \quad$ Discussion 298

4.1 Is there any future for widespread consanguineous marriage? 298

4.2 Consanguineous marriage in historical populations with similar 299

5 Conclusions 301

$\begin{array}{ll}\text { Bibliography } & 303\end{array}$

Appendix: Model specification and implementation details 310 


\title{
Modelling the constraints on consanguineous marriage when fertility declines
}

\author{
Bilal Barakat ${ }^{1}$ \\ Stuart Basten ${ }^{2}$
}

\begin{abstract}
BACKGROUND

Consanguinity - or marriage between close blood relatives, in particular first cousins - is widely practised and even socially encouraged in many countries. However, in the face of fertility transition where the number of cousins eligible to marry declines, how might such constraints on consanguinity develop in the future?
\end{abstract}

\section{OBJECTIVE}

Numerous studies have stated that the practice cannot continue at present levels and in its present form in the face of fertility transition. However, the future impact of fertility transition on availability of cousins to marry has not yet been quantified.

\section{METHODS}

We perform a simulation exercise using past and projected net reproduction rates (NRRs) derived from the UN. We calculate the average number of cousins of the opposite sex as a function of the average number of children, the average probability of an individual having at least one eligible paternal cousin of the opposite sex, and conclude with an examination of constraints on consanguineous marriage in selected countries under different fertility assumptions.

\section{RESULTS}

Current and projected fertility levels in Middle Eastern countries will create challenging constraints on the custom once today's birth cohorts reach marriageable age.

\section{CONCLUSIONS}

Either consanguinity prevalence will diminish significantly, or the institution will be forced to adapt by becoming more coercive in the face of reduced choice or at the expense of other social preferences (such as for an older groom wedding a younger bride). Fertility decline affects prospects for social change not only through its well-

\footnotetext{
${ }^{1}$ Wittgenstein Centre for Demography and Global Human Capital (IIASA, VID/ÖAW, WU). E-Mail: bilal.barakat@oeaw.ac.at.

${ }^{2}$ University of Oxford, United Kingdom. E-Mail: stuart.basten@spi.ox.ac.uk.
} 
Barakat \& Basten: Modelling the constraints on consanguineous marriage when fertility declines

known consequences for mothers but also through shaping marriage conditions for the next generation.

\section{Background}

\subsection{Defining consanguinity}

In terms of clinical genetics, a consanguineous marriage is defined as a union between two individuals who are related as second cousins or closer (Hamamy 2012). The inbreeding coefficient, $F=0.0156$, represents the probability of an individual having a pair of alleles that are identical by descent (Hartl and Clark 1989: 236). As such, second cousins - or a couple whose grandparents were siblings - would have an inbreeding coefficient of 0.0156 (see Figure 1). Figure 1 shows six of the most common types of consanguineous marriage. First cousin marriage, one of the most widespread forms of consanguineous marriage, has an inbreeding coefficient of $F=0.0625$. Hamamy et al. (2011) observe a practice in some Arab communities to marry double first cousins, and in South India uncle-niece marriages are not uncommon. In each of these cases the inbreeding coefficient reaches $F=0.125$. However, it should be noted that in populations with a high degree of consanguinity so-called 'complex consanguinity loops' can arise from successive generations of cousin marriage which can lead to even higher inbreeding coefficients.

'Inbreeding', particularly over numerous generations, has been widely reported to have negative implications for childhood mortality and morbidity (Jurdi and Saxena 2003, Bittles 2001). While it is often difficult to isolate the consanguinity-related genetic impact from other socio-demographic factors, mortality differentials of high statistical significance have been confirmed using meta-analysis (Bittles and Black 2010a).

Both sacred and secular boundaries are set with regard to consanguineous marriages across the world. First cousin marriage is, for example, proscribed by the Greek and Russian Orthodox Church and within Sikhism (Bittles and Black 2010b). In the civil code, however, only a handful of countries proscribe cousin marriage. China prohibited first-cousins marriage in the 1981 Marriage Law (with some exceptions for ethnic groups) while North Korea banned marriage between blood relatives up to third cousin under the auspices of the 1994 Family Law (Bittles and Black 2010b). ${ }^{3}$ Finally,

\footnotetext{
${ }^{3}$ In the case of China, however, Wang et al. (2002) observe that the family planning restrictions in place, and hence the low fertility prevalent especially in urban centres, had effectively reduced the potential number of marriageable first cousins.
} 
first cousin marriage is illegal in 31 of the 50 states of the US (Ottenheimer 1996, Paul and Spencer 2008, Bittles and Black 2010b).

Figure 1: Categories of consanguineous marriage

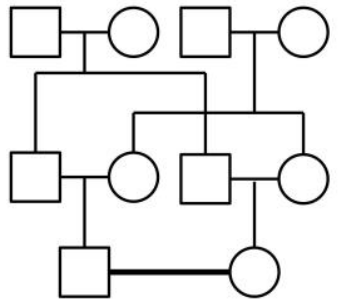

Double first cousins $F=0.125$

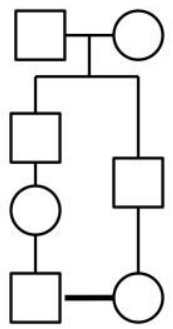

First cousins once removed $F=0.0313$

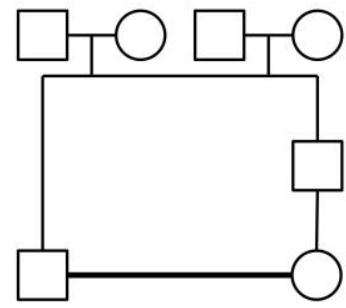

Uncle-niece

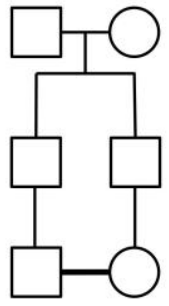

First cousins $F=0.0625$

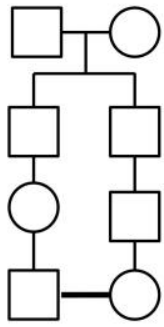

Second cousins $F=0.0156$

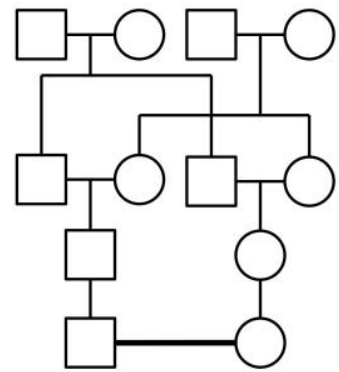

Double second cousins $F=0.0313$

Source: adapted from Hamamy 2012

Consanguineous marriages are widely practised and even socially encouraged across the Middle East and North African countries, as well as in South Asia and among immigrant and specific religious groups elsewhere (Darr and Modell 1988, Bittles 2003). Recently collected sample prevalence rates in the different regions of these countries include 23\%-78\% in Iran (Abbasi-Shavazi et al. 2008), 25\%-50\% in Iraq (COSIT 2005), 15\%-63\% in Syria (Othman and Saadat 2009), 15\%-39\% in Turkey (Koc 2008), and 25\%-55\% in Egypt (Khayat and Saxena 2005). Rates of around 40\%$60 \%$ have also been reported in Sudan, Saudi Arabia, Jordan, Tunisia, and Yemen 
(Khayat and Saxena 2005). Furthermore, anthropological evidence from Sub-Saharan Africa and South East Asia suggests high prevalence rates that the lack of quantitative data is unable to document (Bittles and Black 2010a). Overall, it has been estimated that in countries where Islam prevails, consanguineous marriages generally account for between 20\%-50\% of all marriages (Bittles et al. 1991, Bittles 1994), although any causal link between Islam/Islamisation and consanguinity has been strongly contested (e.g., Korotayev 2000). Indeed, between $20 \%-45 \%$ of unions in South India, where Hinduism prevails, are between blood relatives while a similar trend, driven by sociocultural customs, has been identified among some communities in West and South Asia, such as Buddhists, Christians, Jews, Parsees, and Druze (Bittles et al. 1991, Bittles 1994). Bittles and Black (2010a) estimate that $10.4 \%$ of the global population (in $2010)$ is related as second cousins or closer $(F \geq 0.0156)$.

Beyond geography, Bittles and Black (2010b) identify a number of demographic and social correlates of consanguinity, namely rural residence, more traditional lifestyle, lower socioeconomic status, family tradition of consanguineous marriage, low level of maternal education, younger maternal and paternal ages at marriage and lower spousal age differences, younger maternal age at first birth, shorter birth intervals, extended maternal reproductive spans, and larger completed family sizes.

While first-cousin marriages are the most common form of such marriages, there is an important difference between 'cross-cousin' and 'parallel cousin' or 'ortho-cousin' marriages. A 'cross-cousin' is the child of the mother's brother or of the father's sister, while a 'parallel-cousin' is the child of the father's brother or the mother's sister (see Murphy and Kasdan 1959, Ember and Ember 1988). Globally, it has been suggested that the majority of consanguineous marriages are, in fact, 'cross-cousin' marriages. Indeed, Korotayev (2000:395) observes that the "overwhelming majority of crosscousin marriages appear among the Islamic cultures of North Africa, and those of West and Central Asia". The crucial difference between the two forms of marriage is that in exogamous unilineal descent groups, parallel cousins belong to one's own descent group, while cross cousins do not. Some scholars argue maintenance of property rights is just one manifestation of an event that symbolises a more general sense of a 'solidarity' with one's father's lineage (e.g., Holy 1989), although such simple interpretations have been questioned (e.g., Ahmed 1990). Furthermore, of these parallel-cousin marriages, 'paternal parallel' marriages, or marriage to the father's brother's daughter, are indeed the predominant form of consanguineous union. ${ }^{4}$

As Table 1 indicates, within contemporary Arab countries 'paternal parallel' marriages represent the predominant form of consanguineous union. However, important differences can be observed between both countries and socio-economic

\footnotetext{
${ }^{4}$ Such marriages are also known as 'preferential partrilateral parallel cousin marriage', 'Type I', and 'FBD' marriages. In Arabic, such weddings are known as 'Bint amm'.
} 
groups. In a 2004 study of consanguineous marriages in Sana'a (Yemen), for example, where the total incidence of consanguinity was $45 \%$ with $72 \%$ being first-cousin marriages, such 'paternal parallel' marriages accounted for only $49 \%$ of the total, with cross-cousin marriages accounting for a further 33\% (Gunaid, Hummad, and Tamim 2004). Similarly, in Beirut, a 1984 study by Klat and Khudr observed that while consanguineous - mainly first-cousin - marriages are frequent, the preference for 'paternal parallel' marriages was, indeed, declining. On the other hand, numerous studies have identified extremely high levels of paternal parallel marriages among lower income, rural, and Bedouin tribal communities (Khlat et al. 1986; Radovanovic, Shah, and Behbehani 1999; Raz and Atar 2004).

Table 1: $\quad$ Preferred patterns of first cousin marriage in different Arab societies, developed and elaborated from Bittles and Hamamy 2010

\begin{tabular}{|c|c|c|c|c|c|c|}
\hline \multirow[t]{2}{*}{ Country } & \multicolumn{2}{|c|}{ Parallel-cousin (\%) } & \multicolumn{2}{|c|}{ Cross-cousin (\%) } & \multirow{2}{*}{$\begin{array}{c}\text { All first } \\
\text { cousin } \\
\text { unions (\%) }\end{array}$} & \multirow[t]{2}{*}{ Source } \\
\hline & Paternal $^{a}$ & Maternal $^{b}$ & Paternal $\left.\right|^{c}$ & Maternal $^{d}$ & & \\
\hline \multirow{2}{*}{$\begin{array}{l}\text { Lebanon } \\
\text { Jordan }\end{array}$} & 37.4 & 22.5 & 10.4 & 29.7 & 14.1 & Khlat 1985 \\
\hline & 62.8 & 9.9 & 7.7 & 11.3 & 32.0 & $\begin{array}{l}\text { Khoury and } \\
\text { Massad } 1992\end{array}$ \\
\hline UAE & 64.9 & 8.4 & 12.2 & 14.5 & 26.2 & $\begin{array}{l}\text { Al-Gazali et } \\
\text { al. } 1997\end{array}$ \\
\hline Israel & 48.2 & 20.3 & 13.5 & 17.7 & 24.3 & $\begin{array}{l}\text { Jaber et al. } \\
2000\end{array}$ \\
\hline Yemen & 48.9 & 18.1 & 14.2 & 18.8 & 29.4 & $\begin{array}{l}\text { Gunaid et al. } \\
2004\end{array}$ \\
\hline Qatar & 36.8 & 21.1 & 14.2 & 26.8 & 34.8 & $\begin{array}{l}\text { Bener and } \\
\text { Alali } 2004\end{array}$ \\
\hline Palestinian & & & & & & Assaf and \\
\hline Territories & 47.9 & 17.6 & 20.1 & 14.4 & 14.4 & $\begin{array}{l}\text { Khawaja } \\
2009\end{array}$ \\
\hline
\end{tabular}

Notes:

a Father's brother's sister, $F=0.0625$

b Mother's sister's daughter, $F=0.0625$

c Father's sister's daughter, $F=0.0625$

d Mother's brother's daughter, $F=0.0625$ 
Of course, consanguinity needs to be sited in a wide array of family demographic systems within which it has an important interplay. Consanguinity and polygyny have traditionally co-existed in a number of populations, although the prevalence of the latter has often been exaggerated (Chamie 1986). For example, prevalence rates in North Africa, Palestine, and Syria are between 3\%-5\% (Tabutin and Schoumaker 2005), while in some sub-Saharan groups levels of polygyny can range between $20 \%-50 \%$ (Timaeus and Reynar 1998). However, the theoretical relationship between fertility change and polygynous marriage has primarily been considered at the micro-level, i.e., changing fertility levels by marriage order within relationships, rather than fertility at the population level. Cahu et al. (2011), however, find that women in polgynous relationships tend to exhibit lower lifetime fertility than those in monogamous relationships.

\subsection{Recent trends in consanguinity}

Globally, rates of consanguinity are declining, with marked reductions in more industrialised countries - coupled, of course, with the combined proscription and demographic conditions in China, which clearly affect global prevalence rates. However, in some countries the present-day rates are, in fact, higher than those of the preceding generation. In Qatar, to take one example, prevalence rates for consanguineous marriages are higher among the current generation compared to their parents, particularly regarding double first cousin $(3.1 \%$ versus $1.2 \%)$ and first cousin marriages (34.8\% versus 26.7\%) (Bener and Alali 2006).

Three discrete sets of mechanisms have been identified to highlight the appeal of consanguineous marriage across the greater Middle East (Weinreb 2008). Firstly, women in consanguineous unions are better able to assert a superior kinship position: unlike exogamous wives who can be more easily divorced and whose children more explicitly belong to their husband's family (Tillion 1983, Mernissi 1987), endogamous wives have a larger local support network and are better able to take advantage of 'kinship solidarity' (Abu-Lughod 1986, Davis 1983). Secondly, in patrilineal marriages property remains within the lineage - a feature especially important in rural communities (Bittles and Black 2010b). Thirdly, the initial bridal payment is generally lower (Dahl 1997). Finally, endogamous marriages are "expressive acts (that) make pronouncements about the value of kinship of solidarity" (Holy 1989, p. 114). These cultural factors might relate to trust and familial loyalty, the purity of the bloodline, and, at a clan level, the security of the group (Schultz and Lavenda 2000). As Bittles (2003) observes, for impoverished rural areas characterised by low levels of maternal education, early age at marriage and first birth, short birth intervals, and longer 
reproductive spans, the socioeconomic benefits of consanguineous marriage often outweigh the biological disadvantages.

Finally, a body of literature in political and social science has called attention to other issues, including the so-called 'republic of cousins' where the interests of the extended family or group outweigh the state or other economic enterprises (Tillion 1983). Given the often high degrees of political uncertainty in many areas where cousin marriage is high, this 'retreat' to the kin group could be a rational response.

It is, however, crucial to set apart underlying preferences for cousin marriage as determined by the social, economic, and cultural factors set out above from the demographic conditions to actualise such a marriage. Indeed, Bittles and Black (2010, p. 1780a) observe that the increased overall prevalence rates in many settings "possibly reflect greater overall survival to adulthood that in turn increases the numbers of marriageable biological relatives". Net population growth among the age groups considered to be of 'marriageable age' has been quite striking over the past few decades as a result of such countries travelling through the first phases of the Demographic Transition (e.g., Rashad 2000). As such, this combination of underlying preferences and favourable demographic conditions can act as a suitable background for the kind of high rates of consanguinity currently visible in many countries in the Middle East and North Africa [hereafter the 'MENA region'] and beyond.

Weinreb (2008) has suggested that perhaps the most important factor in shaping future trends of cousin marriage is the general decline of fertility. Even traditional societies where consanguinity is common have witnessed a marked, and in some cases dramatic, decline in fertility in the recent past. That this development diminishes the pool of cousins is obvious. More difficult to intuit is just how quickly the constraints tighten.

In this paper, therefore, we attempt to examine this question of demographic constraints on the future of consanguineous marriage - with an emphasis on the predominant form of paternal parallel marriages - in the context of generally falling fertility rates in countries where such marriages predominate. We tackle this issue through a series of simulation exercises using the 2010 United Nations World Population Prospects. It is important to emphasise, however, that this paper is primarily concerned with the demographic context, or, more precisely, is trying to estimate the extent to which there will be constraints to consanguineous marriage driven by falling fertility rates. In the following section, therefore, we outline the methods and the models used, followed by a presentation of the analysis and results in Section 3. In Section 4 we attempt to interpret the findings in the context of the implications such constraints could have on future trends of consanguinity. 


\section{Methods}

\subsection{Baseline distribution}

The baseline distribution of (inclusive) sibship size is modelled as a Poisson count of the given mean. While this is standard for modelling birth parity, it is less clear that this is appropriate for the number of surviving children. To ensure robust conclusions we therefore tested two extreme alternative specifications. In the first, for a given mean child count $n$, all simulated child counts are fixed at $n$. In the second, they follow a uniform discrete distribution on $[0,2 n]$. While the mean number of cousins is indeed affected to some degree by the choice of distribution, the more relevant implied measures of individual probability of having no male cousin and the maximal aggregate share of females matchable to a cousin are affected very little by the choice of distribution, and less than the variation induced by the other changes to the model specification discussed below. Only at very low child counts does the fixed count model deviate starkly from the Poisson model. However, this is clearly a statistical artefact, because at a fixed child count of one there are always zero aunts and uncles, and therefore zero cousins. Accordingly, we proceed with a Poisson baseline, which is subjected to substantively more meaningful sensitivity analyses, as described below.

For the simple Poisson case, the average number of cousins (all and male only) can be calculated analytically. For a randomly sampled individual, the expected (inclusive) sibship size is equal to $n+1$, where $n$ is the mean number of children. If the number of children were constant (and uncorrelated!) across two generations, a random member of the child generation would have an average of $2 n$ maternal and paternal aunts and uncles, who are parents to $2 n^{\wedge} 2$ cousins, of which an average of $n^{\wedge} 2$ would be of the opposite sex (here the sex ratio is assumed to be balanced) and $\left(n^{\wedge} 2\right) / 2$ would be parallel paternal cousins of the opposite sex. While we do not pursue the analytic approach further, since it does not allow for the interaction of the sensitivity tests below and does not provide any answer to the question of maximal matchable share (and finally because, as Le Bras notes (1973, p. 12), if in any case we need to solve the integrals of the complete analytic solution through simulation we might as well simulate the phenomenon of interest directly), it serves as a check on the baseline simulation.

\subsection{Model specification adjustments}

The overall strategy is to examine variation in the outcomes induced by varying the model specification at a given average number of children. Accordingly, where ranges 
are indicated in the figures below these are not stochastic confidence intervals, but indicate the range of values across the different model specifications where each value is a mean across simulation runs for a given model.

\subsection{Sex ratio}

The (tertiary) sex ratio is varied across the values of $45 \%, 50 \%$, and $55 \%$ male, where these probabilities are applied independently to simulated children (a stopping rule is modelled independently, see below). In terms of the more conventional sex-ratio measure of $x$ males per 100 females, these correspond approximately to values of $x=82$, 100 , and 122 . This represents a fairly extreme spread. In particular it greatly exceeds the range observed (for secondary sex ratios) at the national level in the countries in which consanguinity is widespread, in order to guarantee coverage of the sex ratios that may characterise the specific sub-populations which practise cousin marriage, and to allow for further distortions due to differential infant and child mortality. Since ultimately we are interested in characterising the relationship between consanguinity constraints and declining fertility, migration-induced distortions to the sex ratio are of little interest here.

\subsection{Son preference stopping rule}

Sex-selective abortion may not be available or socially acceptable even in the presence of a strong son preference. Indeed, the sex ratios at birth among the countries with the highest prevalence of cousin marriage are unremarkable. It is therefore necessary to also account for son preference that manifests itself in the form of a stopping rule. In other words, to model a behavioural pattern where those couples who do have children do not stop in their parity progression before they have had at least one son. In order to generate such child distributions at a given mean child count, the initial segment of daughters (which might be zero) is modelled as a geometric distribution, and, following the addition of the first son, a Poisson-distributed number of births (of independent sex) is added, where the mean of the Poisson distribution is chosen to bring the overall mean up to the given level.

It may seem as if this model only works if the overall mean number of children is greater than or equal to two, because in the simplest case the mean number of initial daughters is one, so the initial daughters together with the first son already lead to a mean of two. However, as can be seen below, this is no longer the case when the degree of childlessness is varied. While this model is not perfect in that it does not allow, as an 
example, for couples who have several daughters but ultimately never have a son this is arguably extreme since in reality son preference is unlikely to be this absolute and universal. As such, it arguably provides an indication of the amount of variation that may, at most, be expected to be contributed by son preference (or indeed, by non-iid ${ }^{5}$ births more generally).

\subsection{Childlessness}

The proportion childless generated by the Poisson distribution is scaled up or down proportionally by factors 1.5 (high), 1 (default), and 0.5 (low), respectively. The nonzero child counts are then drawn from a zero-truncated Poisson distribution with a suitably scaled mean to maintain the same overall mean across all levels of childlessness.

\subsection{Correlated sibling fertility}

By default, child counts are drawn independently for siblings in the parent generation. An extreme alternative scenario is also simulated where child counts are perfectly correlated among siblings. In other words, all aunts and uncles have the same number of children (and the same as ego's parents). Even though this is extreme it hardly affects the results, suggesting that more elaborate correlation models are unlikely to change the conclusions. A possible correlation between the child count for the grandparents' and parents' generations is ignored for the reason that we want to be able to set both generations' average number of children independently, which rules out the extreme bounding case of perfect correlation across generations. A possible extension would consist of using a bivariate Poisson distribution, but this option is not pursued here, given the overall robustness of the results to the distributional specifications already tested.

\subsection{Selectivity}

While the above specification parameters affect the 'hard' structure of cousinships, from the perspective of union formation it is clear that - even disregarding the question of competition and which cousins are already married to someone else - the total

\footnotetext{
${ }^{5}$ Independent identically distributed
} 
number of cousins of the opposite sex is an overestimate of the number of potential matches. Even in settings where marriages are socially arranged, and even if the bride had no autonomous say in the decision, not every dyad of female and male cousins would be considered eligible. The age differential might be considered inappropriate, and, more specifically, there may be a strong preference for the groom to be older than the bride. This alone cuts the number of 'eligible' cousins in half, on average. ${ }^{6}$ The male cousin may be unattractive to the potential in-laws for any number of reasons, and there may be some tension between the parents of the cousins. Finally, some cousins may, in fact, be 'milk siblings', or breastfed by the same woman - a common practice in many developing countries (Parkes 2005). Under these circumstances they may not be allowed to marry.

Here, we consider scenarios where a given female-male dyad of cousins is considered 'eligible' with probability 1 (no selection), 50\%, or $25 \%$. Arguably, even the latter is generous, especially if any kind of agency is assumed on the part of the potential bride. As a result all of these parameters are argued to provide conservative estimates of the constraint on consanguinity, and the "no selection" case a hard upper bound.

\section{Analysis and results}

\subsection{Overall relationship between fertility and pool of male cousins}

As can already be deduced from the analytic formula for the simple Poisson case, there is an order-of-magnitude decline from dozens to a handful in the mean number of cousins of the opposite sex a random female is expected to have, as the average number of number of surviving children declines from above six (a number not uncommon in the parent generation in the region, and in Yemen in particular) to less than two (a level already reached by Iran and the UAE and projected to be reached even by Egypt and Jordan within a generation). This is shown in Figure 2, together with the range resulting from the different combinations of model specification outlined above. This model variation is modest compared to the differences by adult sibship size.

\footnotetext{
${ }^{6}$ This is not true in the case of cross cousins. Given that females tend to marry at a younger age than males, the father's sister's sons would, on average, be older than a female ego, while her mother's brother's sons would tend to be younger.
} 
Figure 2: Average number of male cousins to a random female as a function of average adult sibship size

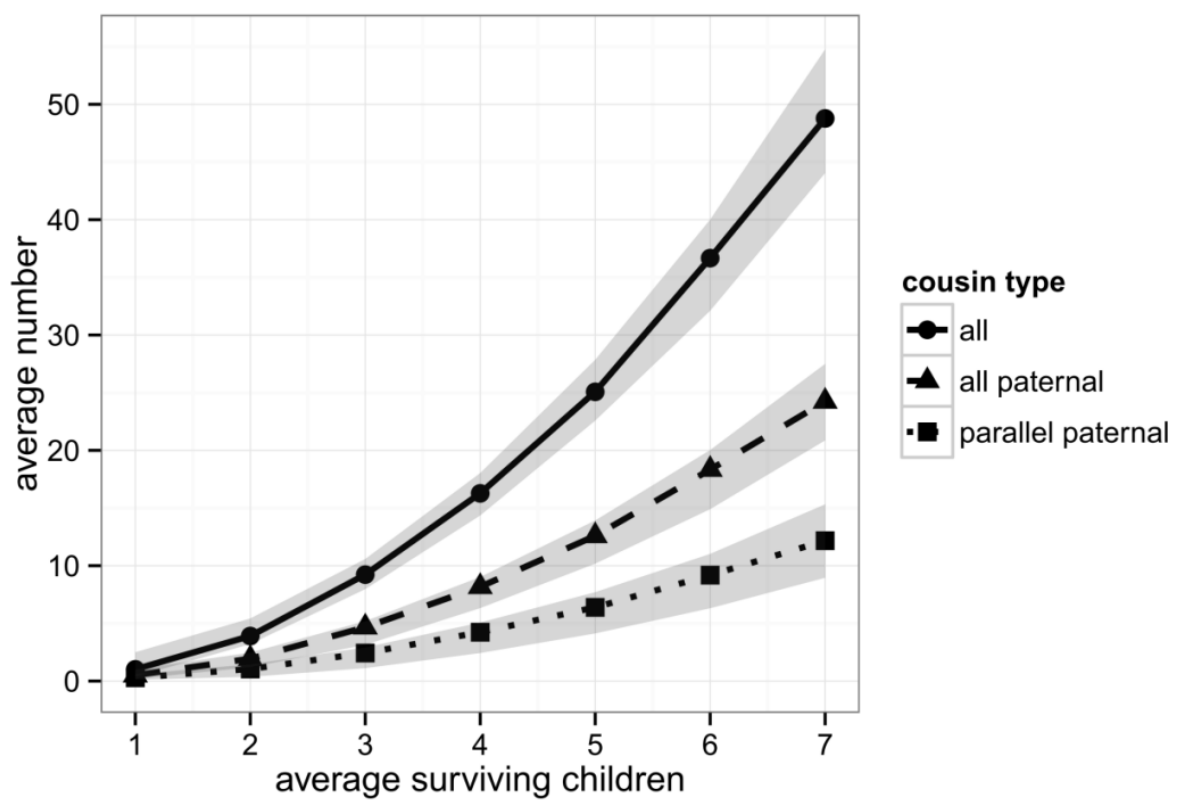

Note: shading indicates range of model-specification induced variation.

The change in the mean number of cousins does not, by itself, necessarily amount to a constraint on cousin marriage, even if it does provide an important sense of the scale of the structural change. The question is whether the diminishing choice pool of male cousins or the diminishing competition from female cousins dominates. We therefore focus our attention on two other simulation outcomes: firstly from an individual perspective, the probability of a random female having no male cousins of the specified type, in which case the question of competition does not arise; secondly from an aggregate perspective, the maximal share of women who could be matched to a male cousin. These two measures are not symmetric opposites: while those without male cousins certainly cannot be matched, the reverse need not be true. Among five sisters with a single male cousin, none of them has no male cousin, but at most one-infive of them can be matched. 


\subsection{Probabilities of no male cousin}

The probabilities of having no eligible cousin of the specified type from the perspective of a random female are displayed in Figure 3. These probabilities cannot be derived from the mean counts in Figure 2 alone because the variation around the mean does matter, as does the distributional effects of different model specifications.

Figure 3: Probability of having no male cousin as a function of average adult sibship size, by selectivity (horizontal panels) and cousin type (vertical panels)

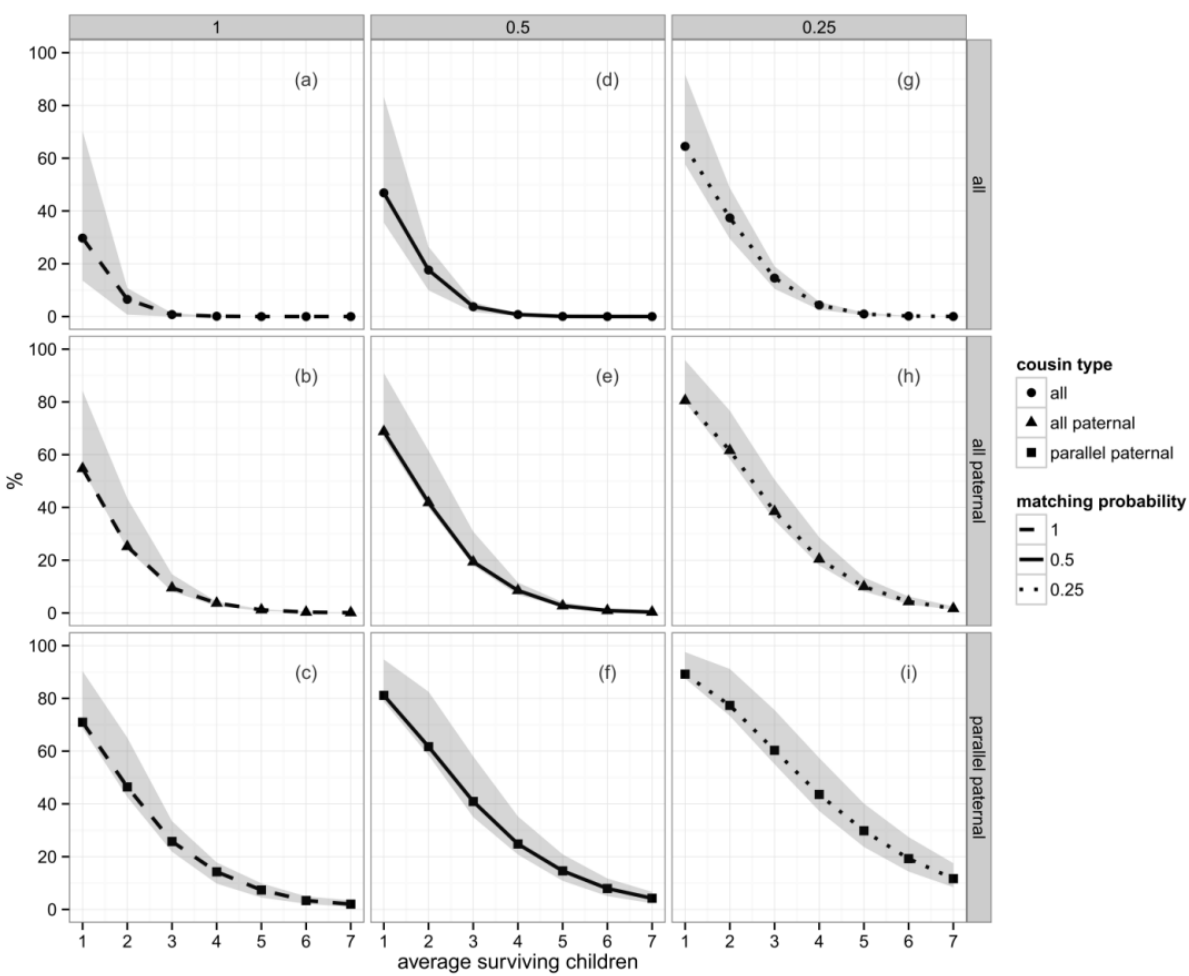

Note: shading indicates range of model-specification induced variation. 
Recall the meaning of the "selectivity" parameter, which is constant along columns of sub-graphs. Panels (a-c) in Figure 3 correspond to the probability of having any male cousin of the specified type at all, without regard to any other factor. It is therefore a highly conservative estimate of the share of women without any suitable cousin. Alone the imposition of an age preference in favour of matching an older groom with a younger bride moves us to the central column, where the estimates are appreciably higher. Allowing, in addition, even for nominal choice on the part of the female (in other words, ensuring she has a choice between at least two candidates, moving us to the right column) greatly increases the share further.

These results suggest that, even disregarding competition (which we turn to next), the most particular types of consanguineous marriage, specifically parallel paternal cousin marriage, is a non-option for a large majority of females once the average number of children drops to two or below, as long as any allowance at all is made for the fact that not any and every male cousin is actually a suitable match - panel (i). Even insisting on the only choice could affect at most about half of women at this level of reproduction, with the other half simply having no male parallel paternal cousin - panel (c). The same is true when a semblance of choice is maintained, but the pool expanded to all first cousins - panel (g). At the other end of the spectrum, it is evident that this particular constraint (of no option of a suitable cousin) all but disappears if preferences regarding the specific type of cousin and his relative age are relaxed and female choice neglected entirely - panel (a). We can also see that at high levels of reproduction this constraint is negligible, even under more restrictive assumptions.

We note that, especially for paternal and parallel paternal cousins and for more stringent selectivity, the baseline model provides a conservative estimate, in that most changes to the model specification lead to a greater proportion of women without the specified type of cousin. In particular, this is true when son preference is introduced.

\subsection{Matching}

The preceding section analysed the share of women who are not exposed to the possibility of cousin marriage on account of not having any male cousins to begin with. Of course, even if a woman does have one or more male cousins, none of them might be 'eligible'. An important factor that makes a cousin ineligible as a partner is simply that he might already be married.

A separate question is therefore what overall share of woman can be matched within a given cousin network. In particular, we estimate the absolute maximum for this share through optimisation (see the technical Appendix for details). 
This maximisation is computationally intensive, and only feasible on closed networks of cousins. Parallel paternal cousinships are naturally closed, because the relationship is symmetric and transitive. If you are my parallel paternal cousin then I am yours, and your parallel paternal cousins are mine, and vice versa. Paternal cousinships alone and a fortiori paternal and maternal mixed cousinships are not closed in this way. In order to perform the maximisation they are therefore restricted to the pool of grandchildren of a single pair of grandparents.

Maximisation requires a single locus of decision-making. It therefore seems plausible that the theoretical maximum may be an overestimate of the maximum share that could actually occur in reality. To investigate this further we compare the maximal share with the share resulting from random matching within the network. In other words, this still assumes an overriding preference for seeking a match within the network, but matches are made locally without following an overall 'global strategy'. This raises the question of what constitutes a 'random' match. Of course, in numerous settings (such as some MENA countries), some women marry within clan or tribal groups so the context of a truly 'random match' in real life is somewhat diminished. However, within cousin networks at least two straightforward interpretations suggest themselves. The first amounts to selecting a match uniformly at random from the set of all potential matches. The second consists of selecting a female uniformly at random, and then one of her available matches (if any; if she has no options, start again). Equivalently, the question is whether sampling the female to match next should be weighted by her number of available matches or not. Neither is self-evidently more plausible than the other. While a greater number of options may indeed be seen as implying a greater chance that one of them is realised in a given period of time there is also a sequential mechanism in operation, because the female cousins do not all reach marriageable age at the same time, but in essentially random order. A priori, one would expect the unweighted randomisation to yield outcomes closer to maximal, because a heuristic optimisation strategy would be to match those with fewer options first, not those with the greatest number of options. This is indeed borne out by the results. However, more striking is the fact that either randomised approach reaches levels fairly close to the maximum ( $c f$. Figure 4). 
Figure 4: Maximal share of females matchable to a male cousin as a function of average adult sibship size, by selectivity, and matching strategy

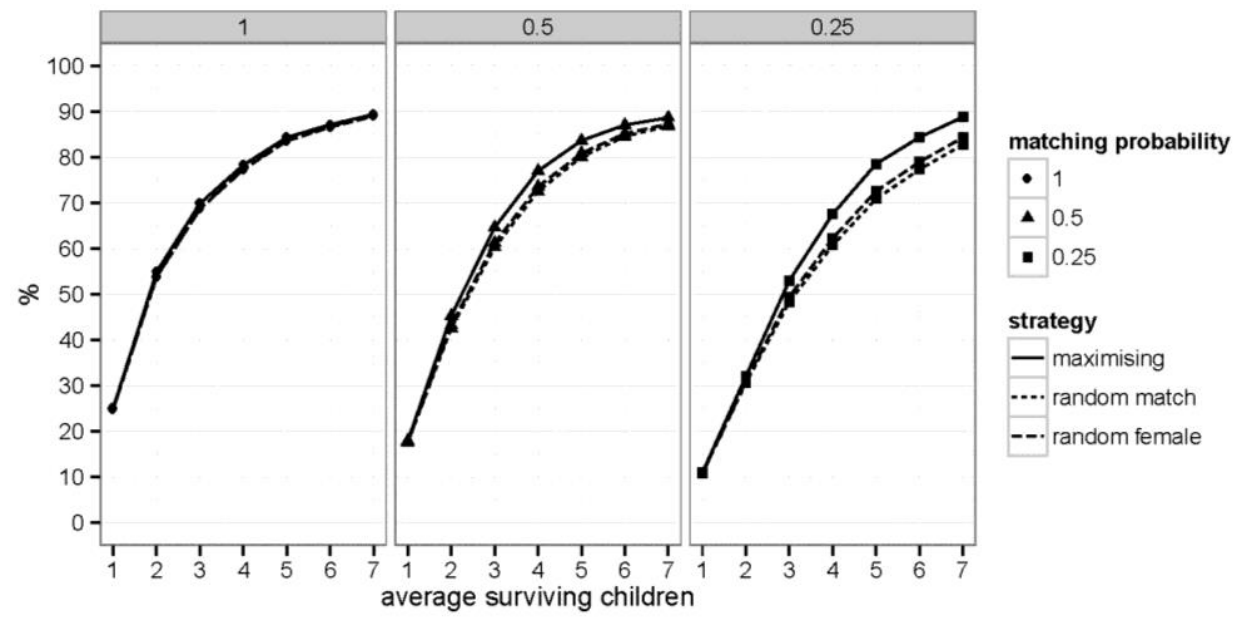

This has both methodological and substantive implications. In terms of methodology, it means that even though optimisation is not feasible on an 'open' network of maternal and paternal cousinships, randomisation by contrast may be feasible. More importantly, it means that the maximal matchable share does not greatly overestimate the realistic upper bound, since getting close to it does not require a hypothetical centralised matchmaking regime. It only requires that each family (or even individual) separately and independently exploits any opportunities within the cousinships examined here first, before turning to either the marriage market outside or other culturally accepted familial links such as cousins 'removed' or second cousins.

Turning to the present results, we can see that the simulated share of females that can at most be matched to a male cousin of the specified type declines strongly as the average adult sibship size decreases. If even modest selectivity is introduced it drops from almost $90 \%$ to $10 \%$ as the number of surviving children moves from seven to one, especially if the sex ratio is skewed towards males. Depending on the model specification the narrower move from four to two children precipitates a decline in the matchable share of between 20 to 40 percentage points.

Inevitably, choice matters. Relaxing all restrictions other than that the partner is a male cousin, still half of all women (and more in the presence of male-biased sex ratios) would be matched to a cousin even at an average child count of two. But insisting on a 
parallel paternal cousin lowers this bound considerably to a large minority, as does the introduction of even modest selectivity.

The aggregate matching constraint can be seen to be tighter than the individual constraint discussed previously. Comparing panel (a) in Figure 3 with panel (b) in Figure 5, note that at a child count of two, fewer than one-in-ten women have no male cousin, but still just over half can be matched to one at the most.

By making comparisons between the panels in Figure 5, we note that the sex ratio affects the results only at high child counts. Conversely, comparisons within rows show that selectivity matters much more at the low end than at the high, as well as affecting the gap between the maximal shares in general and parallel paternal cousin pools.

Also note that, despite the fact that, on average, one quarter an individual's cousins are parallel paternal cousins, the curve for the parallel paternal matching pool and no selection does not correspond to the curve for all cousins with selectivity 0.25 . This is because in the former case whole sibships are included or excluded, whereas in the latter case selection operates individually.

An interesting fact is that increasing selectivity induces a sigmoidal shape in the case of parallel paternal cousin marriage. In other words, the most rapid change in the constraints occurs at medium levels of fertility decline, not at the lowest.

The remaining variation indicated by the shaded areas is - for the parallel paternal cousin case, where it matters - mainly due to the inclusion or not of the son preference stopping rule in the model interacting with childlessness in a fashion elaborated in Figure 6. While even the strict son preference modelled here has very little effect on the maximum matchable share at high child counts, it greatly depresses the matchable share as the number of children drops to two. This is intuitively understandable, since the model implies that as the number of children among parents approaches two, the probability of brothers (whose children would be parallel paternal cousins) goes to zero. The interaction with childlessness confirms this, since lower childlessness at an overall mean child count of two implies the average child count among parents is closer to 2 than it would be at high childlessness and an overall mean of two. In the high childlessness scenario the mean child count of parents greatly exceeds the overall mean across all adults. This is the reason why the stopping rule for parents (which requires a parental mean child count greater than, or equal to, two) is compatible with an overall mean child count of one. 
Figure 5: Maximal share of females matchable to a male cousin as a function of average adult sibship size, by selectivity (horizontal panels), and tertiary sex ratio (vertical panels)

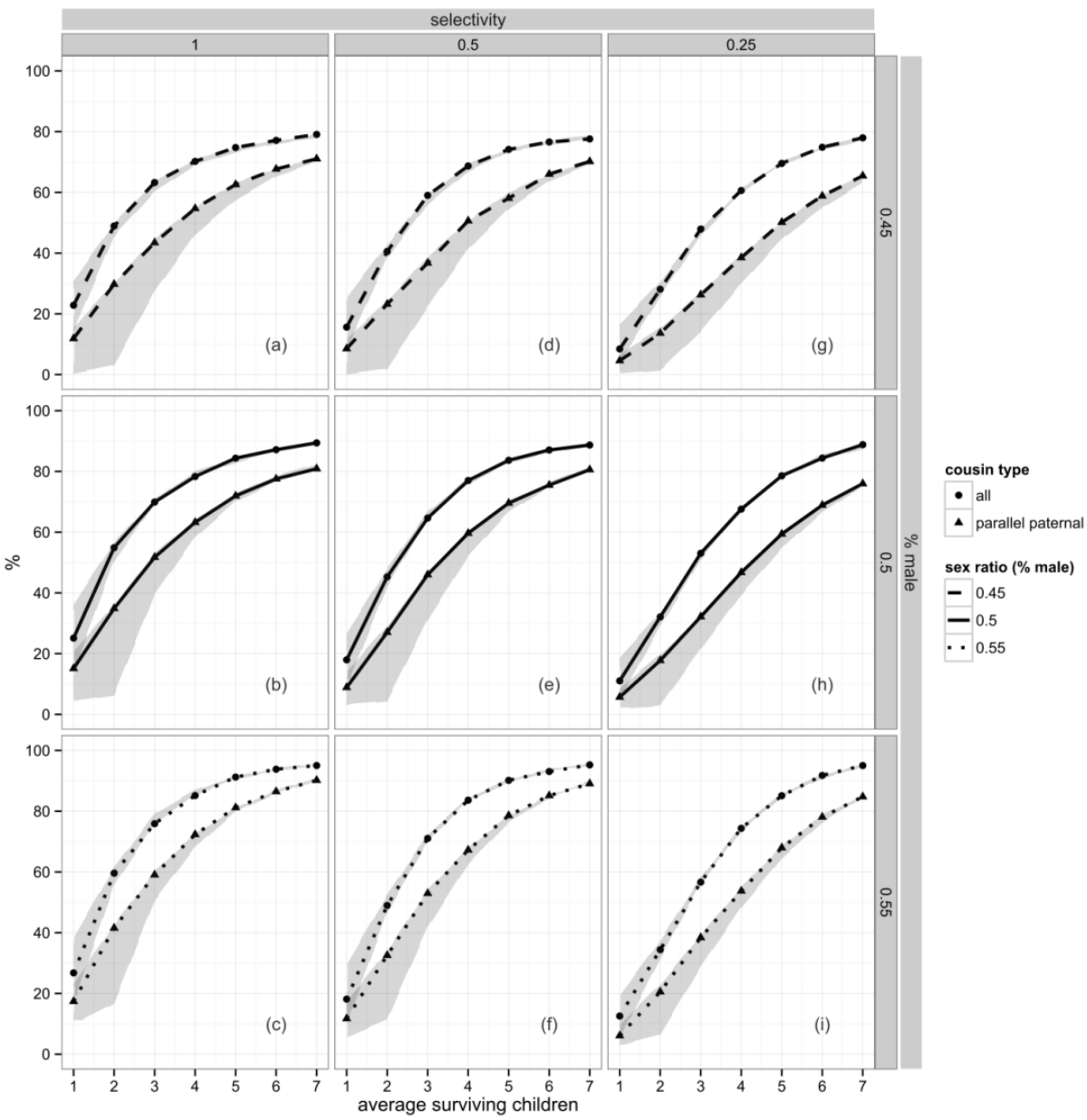

Note: shading indicates range of model-specification induced variation. 
Figure 6: Interaction of childlessness and son preference stopping rule on maximal share of females matchable to a male cousin as a function of average adult sibship size

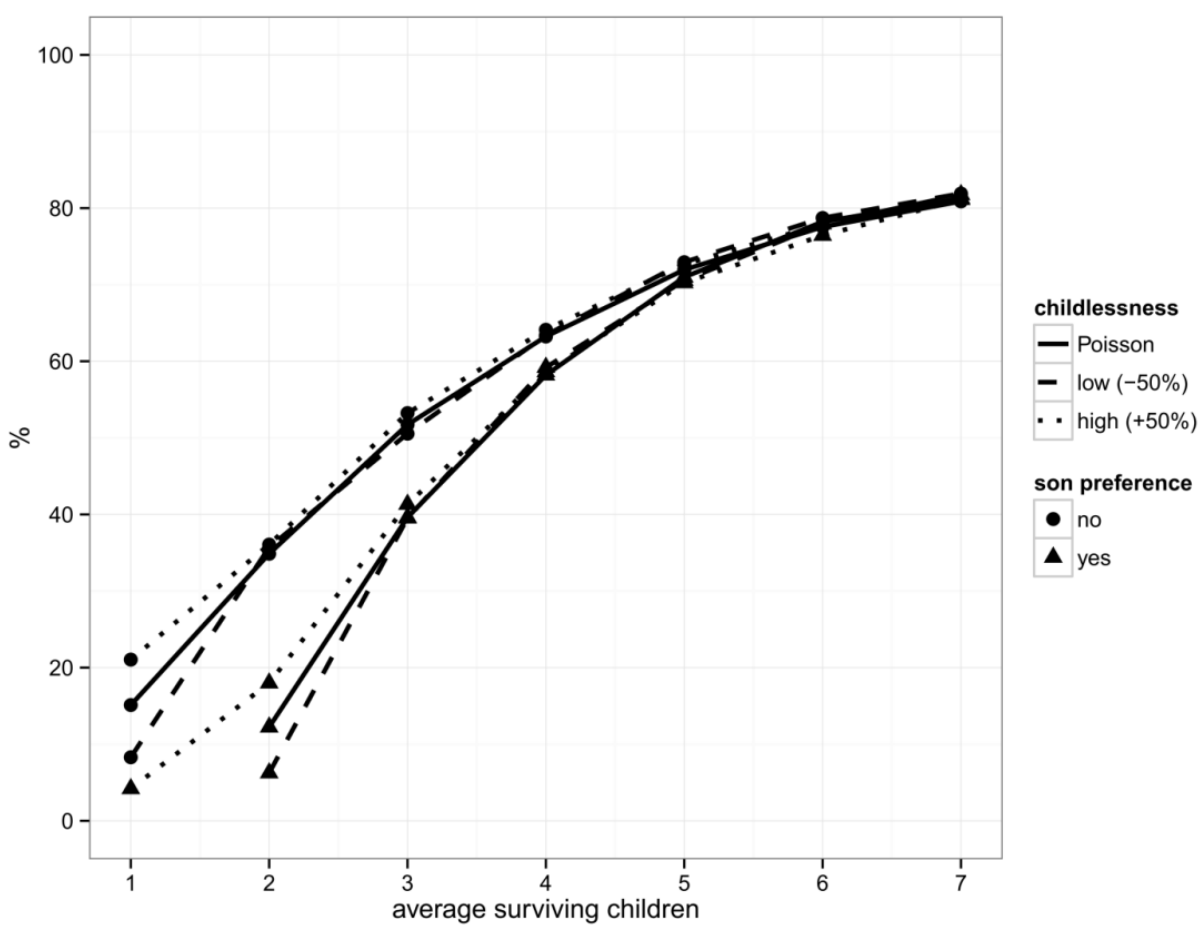

In sum, the decline in the maximal share of women who could theoretically be matched to a cousin shows that the diminishing options as the average number of children declines strongly outweigh the decreased competition. On the contrary, the fact that the decline cannot be mainly attributed to the increasing share of women with no cousin option shows that competition actually increases with declining child count - at least in a combinatorial sense. 


\subsection{Country case studies}

The above simulations assumed constant mean sibship size and structure between generations in order to characterise the constraints on consanguinity as a univariate function of the mean number of children. In real populations the mean sibship size of the parent and child generation may be very different. In order to examine the implications of this we also ran simulations that are calibrated to approximate empirical figures for specific countries. In particular, the average adult sibship size, in other words the average number of surviving children, is set to twice the net reproduction rate (NRR). We employ the NRR instead of the total fertility rate (TFR) in order to account for mortality. While the NRR is normally interpreted as indicating the number of female births a new born female would experience, taking her own mortality into account, in the synthetic cohort this is equivalent to the number of daughters a female at the start of childbearing age (and therefore conditional on having survived to that age) would have, who in turn survive to childbearing age. Accordingly, we take twice the NRR for the years $1980-1985$ as a proxy for the average adult sibship size in the parent generation, that of 2005-2010 for the child generation (i.e., shaping marriage prospects 15-25 years from now), and that of 2030-2035 for the generation of the latter's children (using both the UN's medium and low projections). ${ }^{7}$ This is, of course a relatively crude approximation, but the aim here is not to arrive at forecasts for these specific countries but to highlight the differences between divergent empirical patterns of fertility decline.

The countries chosen are Egypt, with a steady decline in NRR; Iran, with a rapid decline taking it from a level above that in Egypt to one below; and Yemen, with a slow decline at high levels. The results are summarised in Table 2 . The selectivity parameter is set at 50\% (other than for the raw counts) to arrive at somewhat more realistic figures than the purely theoretical assumption that each and every cousin is an eligible match would imply.

In Iran, despite the recent rapid fertility decline, when today's young children reach marriageable age there will be few demographic constraints on consanguineous unions. Up to half of all women could in principle still be married even to specifically a parallel paternal cousin, and more than two-thirds to any type of cousin (including but not limited to parallel paternal ones). The situation for their children is likely to be quite different. Around half of all females may have no eligible male paternal cousin at all, and those with at least one parallel paternal will only number about one-fifth and oneseventh under the medium and low fertility scenarios respectively. Unsurprisingly then,

\footnotetext{
${ }^{7}$ There has been significant discussion regarding the model used in the UN's 2010 World Population Prospects,, especially concerning the assumption that settings with below-replacement fertility at present would see an inexorable rise towards replacement by the end of the century (e.g. Basten 2013). For an alternative, expert-based, fertility assumption for Iran, see Basten et al. 2013).
} 
fewer than one-fifth of females in that generation could be married to their parallel paternal cousin, even if this share were maximised. Even for first cousins of any type, the maximum matchable share may be less than a third (and less than one quarter in the low scenario), which is below some of the estimates for Iran's current actual share.

In Yemen, by contrast, we see few if any hard constraints on cousin marriage of any type, even well into the future, and even taking projected fertility decline into account. Unless much stricter assumptions are made for the selectivity parameter the demographic constraints would make a marriage, even to a parallel paternal cousin, feasible for a large majority of women, even under the low fertility scenario.

Table 2: Results of simulations calibrated to observed and projected NRR figures for Egypt, Iran, and Yemen

\begin{tabular}{|c|c|c|c|c|c|c|c|c|c|c|}
\hline & \multirow[b]{2}{*}{$\begin{array}{l}\text { UN } \\
\text { fertility } \\
\text { variant }\end{array}$} & & \multicolumn{3}{|c|}{ Child generation } & \multicolumn{3}{|c|}{ Grandchild generation } \\
\hline & & & & & $\begin{array}{c}\text { Opposite- } \\
\text { sex cousins } \\
\text { (avg. count) } \\
\text { [parallel } \\
\text { paternal] }\end{array}$ & $\begin{array}{c}\text { Prob. 1+ } \\
\text { male } \\
\text { cousin, } \\
\text { selectivity } \\
0.5(\%) \\
\text { [parallel } \\
\text { paternal] }\end{array}$ & $\begin{array}{c}\text { Maximum } \\
\text { matchable, } \\
\text { selectivity } \\
0.5(\%) \\
\text { [parallel } \\
\text { paternal] }\end{array}$ & $\begin{array}{l}\text { Opposite- } \\
\text { sex cousins } \\
\text { (avg. count) }\end{array}$ & $\begin{array}{c}\text { Prob. 1+ } \\
\text { older male } \\
\text { cousin, } \\
\text { selectivity } \\
0.5(\%) \\
\text { [parallel } \\
\text { paternal] }\end{array}$ & $\begin{array}{c}\text { Maximum } \\
\text { matchable, } \\
\text { selectivity } \\
0.5(\%) \\
\text { [parallel } \\
\text { paternal] }\end{array}$ \\
\hline \multirow{2}{*}{ Egypt } & med & 2.1 & 1.34 & 1 & $\begin{array}{l}11.2 \\
{[2.9]}\end{array}$ & $\begin{array}{c}98 \\
{[66]}\end{array}$ & $\begin{array}{c}73 \\
{[50]}\end{array}$ & $\begin{array}{c}5.22 \\
{[1.36]}\end{array}$ & $\begin{array}{c}87 \\
{[44]}\end{array}$ & $\begin{array}{c}52 \\
{[31]}\end{array}$ \\
\hline & low & . & . & 0.76 & & n.a. & & $\begin{array}{c}4.11 \\
{[1.11]}\end{array}$ & $\begin{array}{c}82 \\
{[36]}\end{array}$ & $\begin{array}{c}49 \\
{[30]}\end{array}$ \\
\hline \multirow{2}{*}{ Iran } & med & 2.73 & 0.82 & 0.65 & $\begin{array}{c}8.8 \\
{[2.2]}\end{array}$ & $\begin{array}{c}98 \\
{[61]}\end{array}$ & $\begin{array}{c}68 \\
{[49]}\end{array}$ & $\begin{array}{c}2.1 \\
{[0.6]}\end{array}$ & $\begin{array}{c}59 \\
{[22]}\end{array}$ & $\begin{array}{c}30 \\
{[18]}\end{array}$ \\
\hline & low & & & 0.42 & & n.a. & & $\begin{array}{c}1.3 \\
{[0.4]}\end{array}$ & $\begin{array}{c}45 \\
{[16]}\end{array}$ & $\begin{array}{c}22 \\
{[14]}\end{array}$ \\
\hline \multirow{2}{*}{ Yemen } & med & 3.35 & 2.38 & 1.58 & $\begin{array}{l}31.8 \\
{[8.0]}\end{array}$ & $\begin{array}{l}100 \\
{[91]}\end{array}$ & $\begin{array}{c}86 \\
{[74]}\end{array}$ & $\begin{array}{l}15.1 \\
{[3.7]}\end{array}$ & $\begin{array}{c}99 \\
{[74]}\end{array}$ & $\begin{array}{c}78 \\
{[59]}\end{array}$ \\
\hline & low & & & 1.34 & & n.a. & & $\begin{array}{l}12.6 \\
{[3.2]}\end{array}$ & $\begin{array}{c}99 \\
{[70]}\end{array}$ & $\begin{array}{c}74 \\
{[58]}\end{array}$ \\
\hline
\end{tabular}

Egypt falls somewhere in between. In the grandchild generation only a small minority of women would be expected to have no eligible cousin to begin with. The probability of being without parallel paternal cousin is much higher though, and a majority of women are expected to fall into this category, or even almost two-thirds of them under the low fertility scenario. Either way, up to half of all women could, in 
principle, be married to a cousin even in the grandchild generation, and slightly less than a third specifically to a parallel paternal one.

\section{Discussion}

\subsection{Is there any future for widespread consanguineous marriage?}

Our simulations have identified a strong link between fertility and the available pool of cousins to marry in a consanguineous setting. Given that fertility is declining rapidly in most countries where rates of cousin marriage are high, would it be fair to suggest that consanguineous marriages have a rather limited future as a significant marriage system in the 'MENA region'?

Indeed, much of the literature on the subject tends to emphasise a number of changing cultural and societal norms, which seem to suggest that fertility decline could simply reinforce a qualitative shift away from consanguineous marriage. Many of these studies seem to be based upon some kind of overarching narrative of 'modernisation' and development. Increased urbanisation, for example, has been cited as a possible factor in driving future declines. Improvements in female education may increase marital exogamy through an increased global view, individual empowerment and (financial) independence, and greater awareness of health risks associated with consanguinity. Some studies suggest that sexual attraction to outsiders as opposed to kin members is likely to be magnetised as a consequence of the increased sexualisation of Arab marital decisions - although this is far from clear (Pastner 1986). Assuming a degree of decision-making independence of bride and groom, this may also be increased by the traits of society associated with modernisation, which include changing preferences for the global/heterogeneous and greater exposure to strangers and the wider world (Jurdi and Saxena 2003). A further issue that is frequently cited in relation to a future decline of preference for consanguineous marriage is increasing awareness of the potential health implications.

However, despite both the context of increased constraints derived from fertility decline and the literature cited above, there are also strong reasons to believe that the answer to our earlier question as to the extent to which consanguineous marriages might have a rather limited future as a significant marriage system in the 'MENA region' could, in fact, be "no". As stated in Section 1, for example, there are a number of reasons why consanguineous marriage can be an entirely rational response to prevailing socio-economic circumstances, irrespective of the tempo of such change. The demographic constraints are just that - 'boundaries' created around the potential pool of mates from which such choices can be made. 
In order to further demonstrate the extent to which a demographically deterministic view of future levels of cousin marriage is not ideal, we briefly turn to explore the historical experience of consanguineous marriage under relatively similar experiences of NRR.

\subsection{Consanguineous marriage in historical populations with similar NRRs}

The NRR in contemporary MENA countries is generally around the 1.2-1.5 mark. This is broadly similar to the rates seen for a number of countries in nineteenth-century Europe (e.g., Italy, Germany, Sweden, England: see Depoid 1941). While contemporary European populations demonstrate low levels of consanguineous marriage, in past populations estimates of such marriages have been higher. Our knowledge of such events is primarily based upon the comprehensive records of Roman Catholic marriage dispensations, although other studies calculated their prevalence from pedigrees and other records (see e.g. Day and Smith 2013). Overall, studies from Europe report generally low rates of consanguineous marriage at the population level. In early twentieth-century Brno, for example, rates were between $0.4 \%-4.7 \%$, with a notable decline from 1930 to 1960 (Zahálková and Preis 1970).

However, when other factors are taken into account such rates increase notably. Some studies identify the role of reproductive isolation in shaping consanguinity - for example Day and Smith (2013) for south-western England as well as Danubio et al. (2004), who identified rates of consanguineous marriage averaging $12 \%$ in nineteenth and early twentieth century L'Aquila, Italy, with an increasing trend in the period $1860-1930$.

More important, however, is the temporal shift in the later nineteenth century towards a "significant increase in inbreeding" in most Western European populations followed by a decrease in the twentieth century (Peña et al. 2002). The decrease is usually associated with broad changes in the economic and social structure of society brought about by inter-related processes of urbanisation, industrializsation, and the breakdown of isolates (Peña et al. 2002, Dahlberg 1929). However, explaining the rise of consanguinity in the nineteenth-century is far more controversial. Demographically speaking, relatively little change in NRRs can be detected across Europe over the course of the nineteenth-century, set, of course, against the backdrop of relatively muted baseline fertility and mortality (e.g., Depoid 1941). Despite this, Hajnal (1963) observed that falling death rates would indeed have contributed to higher rates of consanguineous marriage. Pettener (1985) explicitly identifies a link between inbreeding in the Upper Bologna Apennine with an increased survival in sibships. However, there is a raft of further contextual reasons that could explain why 
consanguinity increased in this period. Indeed, the general causes put forward in the literature tend to relate to either legal developments or shifts in economic circumstances. Some studies, for example, cite the importance of changing regulations regarding property ownership and primogeniture (e.g., Moroni 1967, Morales 1992 in Peña et al. 2002), while others explicitly cite the relaxation of Catholic authorities' attitudes towards grant dispensations for cousin-marriage (Pettener 1985). Other studies within a psychoanalytic framework suggest that Victorians married cousins as surrogates for beloved nuclear family members, driven by strong unconsciously incestuous feelings (Anderson 1986).

Crucially, however, a number of studies explicitly identify a particular cultural, social, or economic context - and some kind of secular shift within it - as the primary predictor of a secular increase (e.g., Jorde and Pitkänen 1991). For example, Bras, van Poppel, and Mandemakers (2009) argue that among the higher strata and farmers in later nineteenth-century Holland kin marriages were commonly practised and played an important role in the process of social class formation. This intimates that kin marriage "served to integrate families in strata of equal social standing during the process of industrialisation and the development of a capitalist market economy" (p.801). However, culture, demography, and geography again play a crucial role for Bras et al., given that the highest rates of consanguineous marriages occur among Orthodox Protestants in the Bible Belt of Holland and in the most isolated areas. For Victorian England, Kuper (2002) argues that "among the middle classes cousin marriage might counteract the division of land through inheritance, or avoid the necessity for very expensive marriage settlements" (p.179). Despite this, cousin marriage in most of these settings was never a mass phenomenon of the Demographic Transition. In Bras' (2009) study, for example, only $2 \%$ of the $1.1 \mathrm{~m}$ marriages studied were between first cousins.

Similarly, other features of the decline of cousin marriage beyond simple 'development' through urbanisation and industrialisation as well as demographic constraints (e.g., Banks 1954) can be observed. This includes an increasingly vociferous public narrative around the perceived negative health consequences of cousin marriage, especially in the United States and United Kingdom (e.g., Ottenheimer 1990, Anderson 1986, Bittles 2009). Furthermore, other structural factors such as the shift from land ownership to other types of moveable capital such as share investment and the subsequent effects on transmission have been identified as contributing factors (Kuper 2002).

In short, the historical experience from Europe strongly supports our hypothesis that demographic contexts might provide the setting for increased rates of consanguineous marriage, but other shifting cultural, social, economic, and political norms and narratives strongly contribute as well. However, the fact that even at the most demographically advantageous points within Transition consanguineous marriage 
rates across historical Europe have been generally low (at the population level) suggests that what we are currently observing in the contemporary MENA countries (and beyond) is something of a novel phenomenon which should be addressed in its own right.

\section{Conclusions}

In our study we have attempted to identify and quantify the demographic constraints on consanguineous marriage - with a particular emphasis on parallel paternal marriages, the predominant form of such marriage in contemporary MENA countries. Previous studies have identified the role of changes in fertility and mortality patterns in shaping both the secular increase and decline - and projected further decline - of consanguineous marriage, but few have attempted to fully simulate such secular changes in an integrated manner.

Our simulations suggest that, demographically, cousin marriage is effectively almost unconstrained at an average fertility of six children. At contemporary levels of fertility in MENA countries - namely of TFRs of around one to three children - the constraints are an order of magnitude higher. This observation holds true from both an individual and social perspective. ${ }^{8}$ As fertility levels are generally projected - and assumed - to decline over the coming decades, it is envisaged that such constraints on cousin marriage may only increase. The overall pattern appears robust to the details of the modelling assumptions. Furthermore, the baseline model provides a relatively conservative estimate of constraints.

However, as we have argued throughout, this does not necessarily mean that observed prevalence will decline, particularly if current rates are well below current constraints. In some countries, however, current prevalence rates are indeed higher than the upper bound implied by their projected fertility decline. Even then a future decline in consanguineous marriage is not inevitable. Conceivably, a recognition of the implied constraints on consanguinity might - on the contrary - contribute to a stalled fertility decline.

A further caveat is that the estimated prevalences quoted here are for percentages of marriage, whereas our estimated 'matchable' shares are, in fact, percentages of women. Currently, in a state where marriage is near-universal this is of little importance. However, if patterns of marriage were to change markedly in the next few decades this could seriously affect the results of the model.

\footnotetext{
${ }^{8}$ Although we do not address polygynous marriages in our model, it can be envisaged that a similar set of conclusions regarding constraints could be reached based upon both the number of available females and possible skewed sex ratios.
} 
In conclusion, therefore, while our study has attempted to identify some of the demographic constraints on consanguineous marriage, prevalence rates will almost certainly rely on a much broader suite of economic, social, cultural, and political drivers and shifting norms. In turn, these drivers and norms will be as diverse and heterogeneous as the countries and cultures which practice widespread consanguineous marriage. While itinerant tribes in one country and the richest, urban communities in another may share similar rates of consanguineous marriage, the broader context as well as even the type of marriage will be extremely different. Demographic modelling alone cannot "tell us the ingenuity and flexibility through which social systems will cope with these changing circumstances" (Guilmoto 2011, p. 40). As such, future shifts in consanguinity rates will be conditioned by contextual variables, albeit within the context of tightening demographic constraints. 


\section{Bibliography}

Abbasi-Shavazi, M., McDonald, P., and Hosseini-Chavoshi, M. (2008). Modernization or cultural maintenance: The practice of consanguineous marriage in Iran. Journal of Biosocial Science 40(6): 911-933. doi:10.1017/S0021932008002782.

Abu-Lughod, L. (1986). Veiled sentiments: Honor and poetry in a Bedouin Society Berkeley: University of California Press.

Ahmed, A. (1990). Review of Ladislav Holy 'Kinship, honour and solidarity: cousin marriage in the Middle East'. Bulletin of the School of Oriental and African Studies 53(2): 347.doi:10.1017/S0041977X00026288.

Al-Gazali, L.I., Bener, A., Abdulrazzaq, Y.M., Micallef, R., al-Khayat, A.I., and Gaber, T. (1997). Consanguineous marriages in the United Arab Emirates. Journal of Biosocial Science 29(4): 491-497. doi:10.1017/S0021932097004914.

Anderson, N.F. (1986). Cousin marriage in Victorian England. Journal of Family History 11(3): 285-301. doi:10.1177/036319908601100305.

Assaf, S. and Khawaja, M. (2009). Consanguinity trends and correlates in the Palestinian Territories. Journal of Biosocial Science 41(1): 107-124. doi:10.1017/S0021932008002940.

Banks, J.A. (1954). Prosperity and parenthood. London: Routledge and Kegan Paul.

Basten, S. (2013). Comparing projection assumptions of fertility in six Advanced Asian Economies; or 'thinking beyond the Medium Variant'. Asian Population Studies 9(3): 322- 331. doi: 10.1080/17441730.2013.836394

Basten, S., Sobotka, T. and Zeman, Z. (2013). Future fertility in low fertility countries. Vienna Institute of Demogaphy Working Papers, 5/2013.

Bener, A. and Alali, K. (2006). Consanguineous marriage in a newly developed country: the Qatari population. Journal of Biosocial Science 38(2): 239-246. doi:10.1017/S0021932004007060.

Bittles, A.H., Mason, W.M., Greene, J., and Rao, N.A. (1991). Reproductive behavior and health in consanguineous marriages. Science 252(5007): 789-794. doi:10.1126/science.2028254.

Bittles, A.H. (1994). The role and significance of consanguinity as a demographic variable. Population and Development Review 20(3): 561-584. doi:10.2307 $/ 2137601$. 
Barakat \& Basten: Modelling the constraints on consanguineous marriage when fertility declines

Bittles, A.H. (2001). Consanguinity and its relevance to clinical genetics. Clinical Genetics 60(2): 89-98. doi:10.1034/j.1399-0004.2001.600201.x.

Bittles, A.H. (2003). The bases of Western attitudes to consanguineous marriage. Developmental Medicine \& Child Neurology 45(2): 135-138. doi:10.1111/ j.1469-8749.2003.tb00917.x.

Bittles, A.H. (2008). A community genetics perspective on consanguineous marriage. Public Health Genomics 11(6): 324-330. doi:10.1159/000133304

Bittles, A.H. (2009). Commentary: The background and outcomes of the first-cousin marriage controversy in Great Britain. International Journal of Epidemiology 38(6): 1453-1458. doi:10.1093/ije/dyp313.

Bittles, A.H. and Black, M.L. (2010a). Consanguinity, human evolution, and complex diseases. Proceedings of the National Academy of Sciences 107(suppl 1): 1779-1786. doi:10.1073/pnas.0906079106.

Bittles, A.H. and Black, M.L. (2010b). Consanguineous Marriage and Human Evolution. Annual Review of Anthropology 39(1): 193-207. doi:10.1146/ annurev.anthro.012809.105051.

Bittles, A.H. and Hamamy, H.A. (2010). Endogamy and consanguineous marriage in Arab populations. In: Teebi, A.S. (ed.). Genetic Disorders Among Arab Populations. Amsterdam: Springer: 85-110. doi:10.1007/978-3-642-05080-0_4

Bras, H., van Poppel, F., and Mandemakers, K. (2009). Relatives as Spouses: Preferences and Opportunities for Kin Marriage in a Western Society. American Journal of Human Biology 21(6): 793-804. doi:10.1002/ajhb.20896.

Cahu, P., Fall, F., and Pongou, R. (2011). Demographic transition in Africa: The polygyny and fertility nexus. Unpublished Working paper. URL: http://congres.afse.fr/docs/2011/410307demographictransitionpolygamy.pdf

Chamie, J. (1986). Polygyny among Arabs. Population Studies 40(1):55-66. doi:10.1080/0032472031000141836.

COSIT. (2005). Iraq Living Conditions Survey 2004, vol. II: Analytical Report. Baghdad: Central Organization for Statistics and IT, Ministry of Planning and Development Co-operation.

Dahl, T.S. (1997). The Muslim family: A study of women's rights in Islam. Oslo: Scandinavian Universities Press.

Dahlberg, G. (1929). Inbreeding in Man. Genetics 14(5): 421-454. 
Danubio, E., Placidi, M,. and Placide, M. (2004). Reproductive isolation in Roio, a pastoral community of the Province of L'Aquila (Abruzzo, Italy) in the period 1800-1965. International Journal of Anthropology 19(3): 239-246. doi:10.1007/BF02447270.

Darr, A. and Modell, B. (1988). The frequency of consanguineous marriage among British Pakistanis. Journal of Medical Genetics 25(3): 186-190. doi:10.1136/jmg.25.3.186.

Davis, S.S. (1983). Patience and power: Women's lives in a Moroccan village. Cambridge: Schenkman.

Day, M. and Smith, M. (2013). Cousin marriage in south-western England in the Nineteenth Century. Journal of Biosocial Science 45(3:) 405-414. doi:10.1017/S0021932012000491.

Depoid, P. (1941). Reproduction nette en Europe depuis l'origine des statistiques de l'état civil. Études et Documents Démographiques, No.1.

Ember, C.R. and Ember, M. (1998). Cross-cultural research. In Bernard, H.R. (ed.) Handbook of methods in cultural anthropology. Walnut Creek, CA: AltaMira Press: 647-690.

Guilmoto, C.Z. (2011). Demography for anthropologists: Populations, castes, and classes. In: Clark-Decès, I. (ed.). A companion to the anthropology of India. Malden, MA: Wiley-Blackwell: 23-44.

Gunaid, A.A., Hummad, N.A., and Tamim, K.A. (2004). Consanguineous marriage in the capital city Sana'a, Yemen. Journal of Biosocial Science 36(1): 111-121. doi:10.1017/S0021932003006138.

Hajnal, J. (1963). Concepts of random mating and the frequency of consanguineous marriage. Proceedings of the Royal Society of London: B 159(974):125-177. doi:10.1098/rspb.1963.0071.

Hamamy, H. (2012). Consanguineous marriages. Preconception consultation in primary health care settings. Journal of Community Genetics 3(3): 185-192. doi:10.1007/s12687-011-0072-y. 
Hamamy, H., Antonarakis, S.E., Cavalli-Sforza, L.L., Temtamy, S., Romeo, G., Kate, L.P., Bennett, R.L., Shaw, A., Megarbane, A., van Duijn, C., Bathija, H., Fokstuen, S., Engel, E., Zlotogora, J., Dermitzakis, E., Bottani, A., Dahoun, S., Morris, M.A., Arsenault, S., Aglan, M.S., Ajaz, M., Alkalamchi, A., Alnaqeb, D., Alwasiyah, M.K., Anwer, N., Awwad, R., Bonnefin, M., Corry, P., Gwanmesia, L., Karbani, G.A., Mostafavi, M., Pippucci, T., Ranza-Boscardin, E., Reversade, B., Sharif, S.M., Teeuw, M.E., and Bittles, A.H. (2011). Consanguineous marriages, pearls and perils: Geneva International Consanguinity Workshop report. Genetic Medicine. 13(9): 841-847. doi:10.1097/GIM.0b013e318217477f.

Hartl, D.L. and Clark, A.G. (1989). Principles of population genetics. Sunderland, MA: Sinauer Associates.

Holy, L. (1989). Kinship, honour and solidarity: Cousin-marriage in the Middle East. Manchester: Manchester University Press.

Jaber, J., Halpern, G.J., and Shohat, T. (2000). Trends in the frequencies of consanguineous marriage in the Israeli Arab Community. Clinical Genetics 58(2): 106-110. doi:10.1034/j.1399-0004.2000.580203.x.

Jorde, L.B. and Pitkänen, K.J. (1991). Inbreeding in Finland. American Journal of Physical Anthropology 84(2): 127-139. doi:10.1002/ajpa.1330840203.

Jurdi, R. and Saxena, P.C. (2003). The prevalence and correlates of consanguineous marriages in Yemen: similarities and contrasts with other Arab countries. Journal of Biosocial Science 35(1): 1-13. doi:10.1017/S0021932003000014.

Khayat, R.G. and Saxena, P.C. (2005). Consanguinity and its effect on fertility and infant and child mortality in Egypt. Population Association of America Annual Meeting. Philadelphia, PA.

Khlat, M. (1985). Consanguineous marriages in Beirut: time trends, spatial distribution. Social Biology 35(3-4): 324-330.

Khlat, M., Halabi, S., Khudr, A., and Der Kaloustian, V.M. (1986). Perception of consanguineous marriages and their genetic effects among a sample of couples from Beirut. American Journal of Medical Genetics 25(2): 299-306. doi:10.1002/ajmg.1320250215.

Khoury, S.A. and Massad, D. (1992). Consanguineous Marriage in Jordan. American Journal of Medical Genetics 43(5): 769-775. doi:10.1002/ajmg.1320430502. 
Koc, I. (2008). Prevalence and sociodemographic correlates of consanguineous marriages in Turkey. Journal of Biosocial Science 40(1): 137-148. doi:10.1017/S002193200700226X.

Korotayev, A. (2000). Parallel-Cousin (FBD) Marriage, Islamization, and Arabization. Ethnology 39(4): 395-407. doi:10.2307/3774053.

Kuper, A. (2002). Incest, cousin marriage, and the origin of the human sciences in nineteenth-century England. Past and Present 174(1): 158-183. doi:10.1093/past/174.1.158.

Le Bras, H. (1973). Parents, grands-parents bisaieux. Population (French Edition) 28(1): 9-38. doi :10.2307/1530968

Mernissi, F. (1987). Beyond the veil: Male-female dynamics in a modern Muslim society. Bloomington: Indiana University Press.

Morales, B. (1992). Estructura de la consanguinidad en la Diócesis de SigüenzaGuadalajara (1855-1980). Variación histórica, microgeográfica y genealógica. [PhD thesis]. Bilbao: Universidad del País Vasco.

Moroni, A. (1967). Andamento della consanguineità nell'Italia settentrionale negli ultimi quattro secoli. Atti. Associazione Genetica Italiana. XII: 202-222.

Murphy, R.F. and Kasdan, L. (1959). The structure of parallel cousin marriage. American Anthropologist 61(1): 17-29. doi:10.1525/aa.1959.61.1.02a00040.

Othman, H. and Saadat, M. (2009). Prevalence of consanguineous marriages in Syria. Journal of Biosocial Science 41(5): 685-692. doi:10.1017/S0021932009003411.

Ottenheimer, M. (1990). Lewis Henry Morgan and the prohibition of cousin marriage in the United States. Journal of Family History 15(3): 325-334. doi:10.1177/036319909001500118.

Ottenheimer, M. (1996). Forbidden relatives: The American myth of cousin marriage. Urbana: University of Illinois Press.

Parkes, P. (2005). Milk kinship in Islam: Substance, structure, history. Social Anthropology 13(3): 307-329. doi:10.1111/j.1469-8676.2005.tb00015.x

Pastner, C. (1986). The Westermarck Hypothesis and first cousin marriage: The cultural modification of negative sexual imprinting. Journal of Anthropological Research 42(4): 573-586. 
Paul, D.B. and Spencer, H.G. (2008). 'It's ok, we're not cousin by blood': the cousin marriage controversy in historical perspective. PLoS Biology 6(12): e320. doi:10.1371/journal.pbio.0060320.

Peña, J.A., Alfonso-Sánchez, M., and Calderón, R. (2002). Inbreeding and demographic transition in the Orozco Valley (Basque Country, Spain). American Journal of Human Biology 14(6):713-720. doi:10.1002/ajhb.10085.

Pettener, D. (1985). Consanguineous marriages in the Upper Bologna Appenine (1565-1980). Human Biology 57: 267-288.

Radovanovic, Z., Shah, N. and Behbehani, J. (1999). Prevalence and social correlates of consanguinity in Kuwait. Annals of Saudi Medicine 19(3): 206-210.

Rashad, H. (2000). Demographic transition in Arab countries: A new perspective. Journal of Population Research 17(1): 83-101. doi:10.1007/BF03029449.

Raz, A.E. and Atar, M. (2004). Cousin marriage and premarital carrier matching in a Bedouin community in Israel: attitudes, service development and educational intervention. Journal of Family Planning and Reproductive Health Care 30(1): 49-51. doi:10.1783/147118904322701992.

Schultz, E.A. and Lavenda, R.H. (2000). Cultural anthropology: A perspective on the human condition. New York: McGraw-Hill.

Tabutin, D. and Shoumaker, M. (2005). The demography of the Arab World and the Middle East from the 1950s to the 2000s. Population (English Edition) 60(5): 505-615. doi:10.3917/pope.505.0505.

Tillion, G. (1983). The republic of cousins: Women's oppression in Mediterranean society. London: Al-Saqi Books.

Timæus, I. and Reynar, A. (1998). Polygynists and their wives in Sub-Saharan Africa: An analysis of five Demographic and Health Surveys. Population Studies 52(2): 145-162. doi:10.1080/0032472031000150346.

Wang, W., Qian, C., and Bittles, A.H. (2002). Consanguineous marriage in PR China: a study in rural Man (Manchu) Communities. Annals of Human Biology 29(6): 685-690. doi:10.1080/03014460120157439.

Weinreb, A. (2008). Characteristics of women in consanguineous marriages in Egypt, 1988-2000. European Journal of Population/Revue européenne de Démographie 24(2): 185-210. doi:10.1007/s10680-008-9160-z. 
Demographic Research: Volume 30, Article 9

Zahálková, M. and Preis, A. (1970). Consanguineous marriages in dioceses of Brno, Czechoslovakia. Humangenetik. 8(4): 321-324. doi:10.1007/BF00280331. 


\section{Appendix: Model specification and implementation details}

The simulations were run using the authors' custom code in the $\mathrm{R}$ language for statistical computing. The code is available from the authors on request.

The basic model operates as follows. For a given mean child count, sibships are generated in the simplest case by sampling a sequence of Poisson length of binomials with independent gender probabilities. In other words, sibship size is distributed as $s b s$ $\sim$ Poisson(mu.parents), with Binomial(sbs, $r$ ) sons, where mu.parents is the mean number of surviving children in the parent generation, and $r$ the (tertiary) sex ratio. A total of $s b s$ independent sibships are then generated in the child generation, with a mean of mu.children, and assigned to the siblings in the parent generation in random order. We thus obtain a single simulated 'cousinship', which may be empty. A large set of such cousinships is generated; here, the number of replications in each case was 10,000 , and the smoothness of the results suggests simulation variance in the mean estimates is minimal. The matching analysis uses this sample directly. For the analysis from the perspective of a random female individual, the cousinships can be re-sampled with sampling probabilities proportional to the number of females in the child generation, and then a single member of the parent generation is sampled with probabilities proportional to the number of daughters, whose daughters' perspective (which they share) is analysed.

Adjustments to the basic model occur at the following points. Changes to the sex ratio affect the independent binomial gender assignment of individual children.

Changes to childlessness and son preference lead to a redefinition of how a single sibship is generated (see below). The childless share under the baseline Poisson distribution with mean $m$ is equal to $c l=e^{\wedge}(-m)$. This share is multiplied by $p$ in $\{0.5,1$, $1.5\}$ to give $c l^{\prime}=c l p$, and with this probability a zero count will be generated. The mean required of the truncated Poisson distribution is then $\mathrm{m} /(1-\mathrm{cl}$ ') and determined by an optimisation. As explained in the text, instead of a sampling a sequence of binomials of Poisson length, with independent gender probabilities, under the assumption of a son preference stopping rule, a geometric number of daughters is followed by a first son, and then a standard sequence of subsequent children as above with the appropriately reduced mean.

Intra-family correlation determines whether, in the generation of a cousinship, the number of children is drawn independently for each sibling (in the parent generation), or whether the first draw fixes the number of children for all other siblings (i.e., perfect correlation of family size among siblings).

Selectivity is applied as iid binomial assignments as to whether a cousin is counted (as 'eligible') or not. Paternal and parallel paternal cousins are selected from the simulated overall cousin pool according to their definition. 
The above model encodes some implicit simplifying assumptions not mentioned in the text. These include the assumption that individuals have one mother and one father each, in other words, re-partnering does not occur (and neither does polygyny), and consequently there are no half-siblings. The biggest simplification is to abstract away from age. Incorporating the age dimension would require dozens of additional parametric assumptions, including, but not limited to, marriage rates by age and gender, fertility by age or by marriage duration and birth interval, and acceptable age differences. Few of these have obvious default assumptions. In any case, the results would only be affected through ruling out potential matches due to the simulated age difference, but the most basic constraint of this type, namely insisting on an older groom, is readily approximated by the observation that this will be the case in approximately half the matches, and the effects can therefore already be seen in the generic selectivity parameter.

The matching optimisation was performed by taking advantage of the equivalence to the Maximum Flow Problem by setting up a graph with individuals at the vertices and edges between eligible pairings, and connecting a virtual 'source' to all females and a 'sink' to all males. The computations were performed using the graph.maxflow command in the igraph package. 
Barakat \& Basten: Modelling the constraints on consanguineous marriage when fertility declines 